\title{
The Socio-Cultural Functions of Kazakh Kinship Terms
}

\author{
Muldagaliyeva A. A. ${ }^{1}$, Gumarova Sh. B. ${ }^{1}$, Issabayeva B. K. ${ }^{1}$ \& Zhirenshina K. A. ${ }^{1}$ \\ ${ }^{1}$ al-Farabi State National University, Almaty, Kazakhstan \\ Correspondence: Muldagaliyeva A. A., al-Farabi State National University, al-Farabi, str. 71, Almaty, \\ Kazakhstan. E-mail: aizhan-m@inbox.ru
}

Received: February 6, 2015 Accepted: April 20, 2015 Online Published: June 13, 2015

doi:10.5539/ass.v11n16p80 URL: http://dx.doi.org/10.5539/ass.v11n16p80

\begin{abstract}
This paper reports the results of a study of the Kazakh kinship structure, classification and the socio-cultural functions of the Kazakh kinship terms. The Kazakhs have developed at first glance very complex and many branched kinship bonds with the moral codes, family relationship etiquette, the patterns of rights, duties and responsibilities thus being one of the strongest binding forces. The first and foremost principle of the Kazakh kinship system is the principle of "the seven ancestors"-a particular kind of chain of parent-child links between ancestors and descendants. The principle of 7 ancestors defines marriage rules, sex regulation, and incest taboo. For Kazakhs kinship was one of the strongest survival strategies thanks to which they could save integrity of their country. Every terminologically identified kinship category is associated with a culturally distinctive pattern of behavior which should be followed in relation to EGO.
\end{abstract}

Keywords: nomadic life-way, customs, taboos, kinsman, ancestors, adaptive mechanism, marriage prohibition, collaterality, bifurcation

\section{Introduction}

Kinship bonds are one the most important parts of human life. It is thanks to kinship that every society has to fulfill its vital survival functions: its reproduction in the biological aspect, education and socialization of the offspring. These are fundamental functions which must be consistently and continuously performed if the society intends to continue to exist. Kinship is a biologically inalienable property of human nature irrespective of his geographical and national origin. There hardly ever exists a society which has no kinship system (Bloom, 1981). Human being is born as a son, daughter, grandson, and granddaughter and only later in the course of his life he acquires other functions in the society.

The kinship system of each society is a unique historical development that can be understood only through study of culture and through comparison with the kinship systems of other peoples. A lot can be learnt about culture from the study of kinship systems.

Most of the components of Kazakh ethnic culture are centered on kinship relations. There exist multiple customs, traditions, rituals and taboos related to child upbringing, marriage regulation, norms of behavior between parents and children, siblings, between close and distant kinsmen, etc. Throughout all his life man lives in accordance with them and through them he realizes his significance and worth as a member of a social group. Customs and traditions serve a vital function in the life of Kazakh community; give definition, purpose, reason for being, and a solid foundation. It is a vital survival rule for the community to observe customs and traditions, because their main function and designation is to bring order and solidarity to society, to provide its integrity and unity (Radcliffe-Brown, 1931, 1950). They help the community to understand its past and present. Only on the basis of such an appreciation can community move together to face the uncertainties of the future.

\subsection{The Kazakh Kinship Structure}

Historically nomadic people the Kazakhs have developed at first glance very complex and many branched kinship bonds with the moral codes, family relationship etiquette, the patterns of rights, duties and responsibilities thus being one of the strongest binding forces. It was a crucial adaptive mechanism which guaranteed spiritual and cultural unity, ensured solidarity, peaceful coexistence and stability and helped people survive the severe conditions of the Great Steppe (Arginbayev, 1975). In Kazakh society any individual can be easily located and identified by his membership in a kin group. During long travels across the steppe it enabled them to easily come into contact with their countrymen and feel at home wherever they were. They could always 
find a close or distant relative and count on their support and aid; as a consequence, hospitality became one of the wonderful national traits of the Kazakh people.

The first and foremost principle of the Kazakh kinship system is the principle of "the seven ancestors," the number seven being the holy number. The principle of seven ancestors is a foundation for Kazakh descent groups which is crucial in the evolution of Kazakh tribal society, because historically, it provided an adaptive solution to the problems of maintaining political order and defining rights over land, the land being the main asset of the nomadic pastoralists (Hayek, 1991).

Nomadic kinship is thus based on descent: a particular kind of chain of parent-child links between ancestors and descendants. In fact, it is the backbone of the Kazakh system. Descent is patrilineal, but it doesn't include only men. Both son and daughter are members of their father's patrilineal, but only sons were entitled to continue the descent line. That is why it was important to have sons. Sometimes when a person had no male offspring, he adopted his brother's or other male kinsman's son, since his descent line could cease its existence if he took no action.

Kazakhs are an ancestor worshiping culture. Knowledge of each person's seven forefathers was important for survival, because it clearly marks a person's place in society. Wherever a Kazakh nomad was, no matter what society he was in, he could always find a distant or close relative, who could be either an "atalas"- a relative through one of 7 grandfathers, or a "rulas"- relative through their tribal membership. These relationships create secure material and psychological bonds in the huge region inhabited by nomadic peoples. Under such conditions, a Kazakh is never lonely, a stranger, or without a support network (Argynbaev, 1974).

Secondly, the principle of 7 ancestors is connected with marriage rules, sex regulation, and incest taboo. Sex regulation with Kazakhs extended to the most distant degrees of kinship. Like in many societies Kazakhs couldn't remain indifferent to sex and marriage regulation rules in their society. The marital relationship has always been a major focus of regulation. Marriage to a person who shares a common ancestor within 7 generations is strongly prohibited. According to Kazakh belief, genes are transmitted through 7 generations; a child may bear likeness to one of his 7 forefathers. Marriage prohibition was one of the ways of preserving a healthy genetic pool and assuring reproduction of healthy and sound generation (Muldagaliyeva, 2013).

The third principle of the Kazakh kinship system is that there are three groups of ego's relatives: <zhurts>, ego's own relatives (his father's relatives); $<$ nagashy zhurt $>$ (mother's relatives); and $<$ kain zhurt $>$ (his wife's relatives) (Argynbaev, 1950).

The fourth principle of Kazakh kinship is that within ego's own relatives there are;

The two distinct lines: father's brother's line and the line of the sister's and daughter's generations. With marriage, women remain members of their natal patrilineal, but their children are primarily members of their father's patrilineal.

Kazakh kinship terminology includes a lot of terms. Kinship terminology is a special vocabulary complex, which a native speaker of a language can at once recognize as belonging to this set even if they are used metaphorically. There are various definitions of kinship terms. We use the one given by E.R. Leach (1958). He defines kinship terms as "category words by means of which an individual is taught to recognize the significant groupings in the social structure into which he is born" (Leach, 1958).

There are 7 criteria proposed by Kroeber A. L. (1949) on which terminological differentiation is based:

1. Generation: this criterion is based on a biological foundation. The fact of reproduction automatically put people in different generations: Ego's own generation which includes brothers $<$ aga, ini $>$, sisters $<$ apa, singli, karyndas $>$; a first ascending generation: parent's generation mother, father $<$ ake, sheshe $>$, parent's parent's generation $<$ ata, ana, azhe $>$; and a first descending generation, which include son $<$ ul $>$, daughter $<$ kyz $>$; a second descending generation: granddaughter/son (nemere-zhien), The Kazakh term for daughter $<$ kyz $>$ also means $<$ girl $>$. It suggests that any girl in Kazakh society should be treated like she is a daughter.

2. Gender: this category derives from biological difference, that between male and female. This criterion is widely used by Kazakh kinship terminology except a few terms like, <nemere>-grandchild through a son, $<$ zhien $>$-grandchild through a daughter, $<$ shobere $>$-great- grandchild, $<$ nemene $>$-great-great grandchildren. The ignoring of gender in the second, third and fourth descending generations can, probably, be explained by the fact that these relatives are considered to be too young to be sexually differentiated.

3. Affinity: a distinction is made on the basis of connection through marriage. Kazakhs have a wide range of affinal terms; there are terms for male and female elder relatives and younger relative's spouses, terms for the 
spouse's siblings, wife's parents, for the first and second wives, and for more distant affinal relatives. The abundance of affinal terms demonstrates the significance Kazakhs attach to their in-laws. Each affinal term is associated with a distinctive pattern of behavior. Depending on how Ego calls a relative by marriage he determines how he should behave toward him/her (respect, amity, joking relationship).

4. Collaterality: a distinction is made in the parent's generation between the father's and father's sister's sibling's lines; in ego's generation between ego and his siblings. Father's brother's line is designated by adding the term $<$ nemere $>$ to the terms <aga, apa, ini, singli karyndas $>$ literally "older brother, older sister, younger brother,younger sister". The kinship terms of the ego's own collateral line are : $<$ aga $>$ (older br.), $<$ ini $>$ (younger br.), $<$ nemere aga $>$ a (older cousin- father's brother's son), $<$ nemere ini $>$ (younger cousin), $<$ zhien aga $>$ (older cousin- father's sister's son, <zhien apa>- (older sister-cousin- father's sister's daughter).

5. Bifurcation: the distinction between kinship terms referring to the mother's relatives and father's relatives: mother's relatives are distinguished by adding the word $-<$ Nagashi $>$ to the kinship terms, f.ex., $<$ Nagashi $>$-mother's brother, <nagashi apa $>$ - mother's sister, <nagashi ini $>$, <nagashi singli $>$, <nagashi karyndas $>$-cousins on mother's side, $<$ bole $>$ - cousin -mother's sister's son and daughter, so on.

6. Relative age: relatives of the same generation are distinguished on the basis of their age, in Kazakh: aga- older brother; ini-younger brother; apa-older sister; sinli-younger sister;

7. Gender of linking relative: there are two terms for a younger sister, depending on the gender of a speaker, male- $<$ karyndas $>$, female $-<$ singli $>$. In Kazakh kinship the distinction is made between son's and brother's and daughter's and sister's offspring: $<$ nemere $>$ - son's son and daughter, $<$ zhien $>$ - daughter;s son and daughter.

Kazakh kinship uses all seven distinctions; for comparison, American kinship system uses only four. There is a correlation between the number of distinctions used and the number of kinship terms in the language. Usage of more distinctions yields more kinship terms in the language.

Kinship terms are classified in three different ways: by their mode of use, by their linguistic structure, by their range of applications (Lowie, 1928).

\section{The Classification of Kinship Terms}

As concerns their use, kinship terms may be employed as terms of address and terms of reference.

Kazakh kinship terms are widely used as terms of address in speaking to relatives as well as non-relatives; it is part of the linguistic behavior characteristic of the particular interpersonal relationship. Seniority plays an important role in Kazakh culture, so it is not appropriate for younger people to address older ones by names. The use of kinship terms as the linking function to initiate a conversation does not stop at the boundaries of physical kinship. Actually the Kazakhs use kinship terms to people who are not related to them. In social communication, some of the kinship terms can apply to any person depending on the person's sex and relative age. Terms of address are very often emotionally colored, since they are used in interpersonal relationships. The speaker can express his attitudes, like love, amity, and friendship through modifying kin terms by adding special suffixes, for example: apa+tai, apeke, agatai, ageke.

Terms of reference are more specific. They are used to designate a relative when speaking to a third person; they denote a particular kinship status. Terms of reference are used in kinship analysis, jurisprudence, and family studies.

Linguistic structure is the second way of classification. According to their linguistic structure, kinship terms are primary and compound. There are 14 primary terms, designating immediate relatives; all other kin terms are combinations of primary terms with the modifiers.

The third way of classification is their application. Kinship terms are applied differentially as either denotative or as classificatory (Murdock, 1949). A denotative term is a single kinship category, f. ex. $<$ Ake $>$-father, $<$ ul $>$-son, $<$ kiz $>$-daughter, $<$ zaip $>$-wife, $<$ kelin>-daughter- in-law.

A classificatory term denotes two or more different kinship categories. It arises from ignoring of one or more fundamental distinctions. Most Kazakh kinship terms are classificatory, for example:<apa>-denotes any older female relative, $<$ aga $>$, accordingly, any older male relative. $<$ Zhenge $>$ - wife of any older male relative. These terms ignore the distinction of generation, and retain the distinctions of gender and age.

Kazakh kinship extends four generations above Ego and for four below. The term for the last generation below Ego is $<$ nemene $>$, literally meaning "What is it" and denotes the end of kinship relations. There are two terms designating son's and daughter's offspring. Daughter's children belong to another kin group. In father's generation, father's brother and father's sister are not distinguished by special terms. They are designated by the 
classificatory terms $<$ aga, apa $>$-elder male relative + the component $<$ nemere $>$, originally meaning "grandchild through a son" which in this combination acquires the meaning "paternal relative." Mother's brother and sister are designated by the same terms $<$ aga,apa $>+$ component $<$ nagashi $>$, meaning "maternal relative."

In Ego's generation, there are immediate brothers and sisters $<$ aga, apa, singli, ini,karyndas $>$ and a wide range of elder and younger cousins through father's and mother's brothers and sisters, each distinguished by adding components: <Zhien>-father'sister's side, <nagashi>-mother's brother's, <nemere >- father's brother's children. There is a special term for the cousin through mother's sister- $<$ bole $>$.

The terminology for parent's siblings is of the bifurcate collateral type (Lowie, 1949). There are separate terms for mother's brother, mother's sister. Maternal kin is differentiated from the paternal. Within the paternal kin father and father's brother are members of different lines of descent and are terminologically separated.

The cousin terminology demonstrates the steppe variation of Omaha type; there are terms for patri-cross and parallel cousins and matri-cross and parallel cousins. Consistently with the Omaha system of cousin terminology cross generation links are found: father's sister' child bears the same term as sister's child and daughter's child. (Murdock, 1949) puts Omaha as follows: there are four cousin terms, each of the children of each of the parental siblings bearing a separate term, but father's sister's child <zhien> is terminologically classed with sister's child in the first ascending generation and consequently Ego's sister's child is terminologically equated with his daughter's child. (Murdock, 1949) .But the variation on Omaha is that this term has the same extension as the term $<$ nemere $>$; both are symmetrical in the system. $<$ Nemere $>$ designates Father's brother's son, Brother's son, and Son's son; <zhien> designates Father's sister' son; Sister's son; Daughter's son.

The Omaha system on the steppe assigns the same term to mother's brother, to mother's brother's son and to mother's brother's son's son <nagashi> which is the general term for mother's kin. This terminological pattern reflects the ties with the mother's descent group which in Kazakh society is very strong and long-lasting. A special bond of relationship exists between sister's son and mother's brother, which are affection, familiarity and mutual help. Secondly, this pattern is associated with "dispersal alliance", the term was proposed by Robert Mckinley (1977) which expresses a prohibition against marrying into one's mother's descent group in a patrilineal society.

\section{Socio-cultural Functions of Kazakh Kinship Terms}

Kazakhs have always maintained a unique attitude to children and elderly people. One of remarkable traditions of the Kazakh people is respect for elderly relatives: parents, grandparents, great-grandparents and their siblings, and this tradition are passed on from generation to generation. There are very beautiful rituals and ceremonies connected with memorable events as a child birth and marriage. As a rule, all rituals and ceremonies are accompanied by celebrations which bring together relatives, friends and neighbors. One of them is "Tusau kesu" - the ceremony of cutting strings tied around the baby's legs when he/she makes the first steps.

Marriage is a primary way to create new kinship relationships. In Kazakh culture marriage is a remarkable event, because Kazakhs attach great importance and significance to the birth of a new family. Appearance of a new family means much to everyone: extension of kinship relationships, continuity of the descent line, the addition of new people within kin groups, and the exciting potential for new generations. This remarkable event is accompanied by specific rituals, ceremonies, customs, traditions, and feasts. The associated marriage activities also give meaning, purpose and reason for being, as well making life more colorful!

Kazakhs practice exogamous marriage; endogamy is prohibited. There always has been a fear of interbreeding in Kazakh culture. Exogamic marriage is free of this danger, and it has social benefits of increasing collaboration with the outside groups. It provided the fundamental and immutable rule, ensuring the existence of the group as a group (Levy-Strauss, 1969).

Historically marriage was not random. Each kin group had several other kin groups with whom it exchanged wives. Kazakhs tried to take wives and to give their daughters and sisters to the kin group who had good traditions and good reputation, because in older times, first marriages were predominantly arranged by the parents. In Kazakh culture daughters and sisters have always been the objects of love, respect and protection, because for Kazakhs they were "guests" at home who coming of age will marry and leave for another home in the capacity of $<$ kelin $>$-daughter-in-law, who had to take pains to adjust herself to the new social environment which very often was not at all easy, because she was beginning her life. The term $<$ kyz $>$ - "daughter" also denotes "girl" - any young female, which implies that any girl should be treated like she is a daughter. This means that EGO's behavior to any female member of his kingroup and beyond must be protective, affectionate and friendly. In Kazakh there are four verbs that correspond to the meaning of the English word "marriage." A 
girl marries, in Kazakh, $<$ turmiska shigadi $>$ lit. $<$ begins life $>$ (as if she has not lived up till she marries), a young man marries $<$ uilenedi $>$ lit. $<$ Acquires home $>$.

Paying bride price (kalim) was essential in previous times. The value of kalim differed depending on the characteristics of the prospective bride and the economic status of the families concerned. Often marriage was a collective affair; parents of the bridegroom could count on the help of the relatives to assemble a kalim. Approximately a good kalim could be 150 to 200 sheep and 50 horses, a medium kalim could be 40 sheep and 10 horses. But it must be noted that a kalym was intended to serve as a dowry of the bride. Actually the kalym given to the bride's family comes back as a dowry.

The Kazakh term for daughter-in-law is $<$ kelin $>$-literarally $<$ someone who came $>$. There were and there still are strict expectations of the daughter-in-law's behavior. One such custom was the prohibition on the wife's using the names of her husband's relatives. She was expected to call them by other names that usually are descriptive of personal appearance or characteristics and soon popularized within the kin group. This way she established her affectionate and sisterly contact with her new relatives. Coming of an outsider to the kinship group, especially, if she had good looks, could have certain "unfavorable" consequences (Argynbaev, 1984). This was one of the ways of sex regulation among the kinship group and, in general, modest behavior is considered beneficial for a young lady. There has always been a strict code of conduct for females, in general, and girls, in particular, had to follow. There are a lot of proverbs: f.ex. "A girl should be forbidden to go to 40 houses". There was a big responsibility on the girl, because when she married she represented her family in her husband's kingroup and it was desirable that she had an irreproachable reputation so as not to disgrace her family.

One of the examples of sex regulation rules is that all female cousins through both father and mother are called $<$ older or younger sisters $>$ and any female member whom EGO calls $<$ sister $>$ must be treated, in all respects, as sisters, so sex relations with all sisters are therefore automatically tabooed. For Kazakhs it was and is a matter of great concern to avoid incest, to produce healthy offspring so that to improve the quality and increase the quantity of their population.

Historically, polygamy was frequently practiced by those who could afford it, but the first wife held a superior position. There are specific terms for the first and second wives: $<$ baibishe and tokal $>$, the term for the second wife literally meant $<$ a goat without horns $>$, which meant that tokal held an inferior position in the household.

In Kazakh society polygamy affected the social structure. First, to certain extent, it solved the demographic problems. Kazakhs, especially, men have never been numerous; each man's place in the kinship group was important. The fact that Kazakhs had very strict sex regulation rules means that reproduction itself was strictly regulated.

Further evidence of the importance of kinship bonds is the presence of the levirate. The levirate is when a man dies his wife marries his younger brother or any other male relative within the kin group. The new husband then becomes the guardian of his new wife and his elder brother's children, formerly his sister-in-law. Nowadays it can be practiced only at the will and wish of the partners. The ultimate goal of this custom was to prevent orphan hood of children.

\subsection{The Meticulous System of the Kazakh Kinship Terms}

The following Tables show the comparison between Kazakh and English kinship terms.

Table 1. EGO's own relatives (father's side)

\begin{tabular}{lll}
\hline Relation To Ego & Kazakh Term & English Term \\
\hline Paternal Great Grandfather & Ulken Ata & Great Grandfather \\
Paternal Great Grandmother & Ulken Ana/Azhe & Great Grandmother \\
Paternal Father & Ata & Grandfather \\
Paternal Mother & Azhe & Granmother \\
Father & Ake & Father \\
Mother & Ana, Sheshe & Mother \\
Elder Brother & Aga & Brother \\
Younger Brother & Ini & Elder Sister \\
Sister & Apa/Apke & Younger Sister \\
Singli & Karyndas & Younger Sister \\
Son & Ul & Son \\
\hline
\end{tabular}




\begin{tabular}{|c|c|c|}
\hline Relation To Ego & Kazakh Term & English Term \\
\hline Daughter & Kyz & Daughter \\
\hline Son'S Son/Daughter & Nemere & Grandson/Daughter \\
\hline Grandson'S Son/Daughter & Shobere & Great Grandson/Daughter \\
\hline Great Grandson'S Son/Daughter & Nemene & Great Great Grandson/Daughter \\
\hline Daughter's Son & Zhien & Grand Son \\
\hline Daughter's Daughter & Zhien & Grand Daughter \\
\hline Grand Daughter's Son & Zhienshar & Great Grandson \\
\hline Grand Daughter's Daughter & Zhienshar & Great Grand Daughter \\
\hline Father's Brother & Aga, Ata & Uncle \\
\hline Father's Sister & Apa, Apke & Aunt \\
\hline Father's Brother's Elder Son & Nemere Aga & Cousin \\
\hline Father's Brother's Younger Son & Nemere Ini & Cousin \\
\hline Father's Brother's Elder Daughter & $\begin{array}{l}\text { Nemere Apa, Nemere } \\
\text { Apke }\end{array}$ & Cousin \\
\hline Father's Brother's Younger Daughter(Ego-Woman) & Nemere Sinli & Cousin \\
\hline Father's Brother's Younger Daughter(Ego-Man) & Nemere Karyndas & Cousin \\
\hline Father's Sister's Son(Elder Than Ego) & Zhien Aga & Cousin \\
\hline Father' Sister's Son(Younger Than Ego) & Zhien Ini & Cousin \\
\hline Father's Sister's Daughter(Older Than Ego-Man) & Zhien Apa/Apke & Cousin \\
\hline $\begin{array}{l}\text { Father's Sister's Daughter(Younger Than } \\
\text { Ego-Woman) }\end{array}$ & Zhien Singli & Cousin \\
\hline Brother's Son & Nemere Ini & Nephew \\
\hline Brother's Daughter & Nemere Sinli & Niece \\
\hline Sister's Son & Zhien Ini & Nephew \\
\hline Sister's Daughter & Zhien Singli & Niece \\
\hline
\end{tabular}

Table 2. EGO's mother's relatives

\begin{tabular}{lll}
\hline RELATION TO EGO & KAZAKH TERM & ENGLISH TERM \\
\hline Mother's great grandfather & Ulken nagashy ata & Great uncle \\
Mother's great grandmother & Ulken nagashy apa/azhe & Great aunt \\
Mother's father & Nagashy ata & Grand uncle \\
Mother's mother & Nagashy apa/azhe/sheshe & Grand aunt \\
Mother's brother & Nagashy & Uncle \\
Mother's sister & Nagashy apa/apke & Aunt \\
Mother's brother's son(older to EGO) & Nagashy aga & Cousin \\
Mother's brother's son(younger to EGO) & Nagashy ini & Cousin \\
Mother's brother's daughter(older than EGO) & Nagashy apa/apke & Cousin \\
Mother's brother's daughter(younger to EGO-woman) & Nagashy singli & Cousin \\
Mother's brother's daughter(younger than EGO-man) & Nagashi karyndas & Cousin \\
Mother's sister's son(older than EGO) & Bole aga & Cousin \\
Mother's sister'son(younger than EGO) & Bole ini & Cousin \\
Mother's sister's daughter(older than EGO) & Bole apa/apke & Cousin \\
Mother's sister's daughter (younger than EGO-woman) & Bole singli & Cousin \\
Mother's sister'daughter (younger than EGO-man) & Bole karyndas & Cousin \\
\hline
\end{tabular}

Table 3. EGO's wife's relatives

\begin{tabular}{lll}
\hline Husband & Koueu,Er. & Husband \\
Wife & Zaip,ayiel & Wife \\
\hline Husband's father & Ata & Father-in-law \\
Husband's mother & Ene & Mother-in-law \\
Wife's father & Ata & Father-in-law \\
Wife's mother & Ene & Mother-in-law \\
Daughter's husband & Koueu bala & Son -in- law \\
\hline
\end{tabular}




\begin{tabular}{lll}
\hline Husband & Koueu,Er. & Husband \\
Wife & Zaip,ayiel & Wife \\
\hline Son's wife & Kelyn & Daughter-in-law \\
Elder brother's wife & Zhenge & Sister-in-law \\
Elder sister's husband & Zhezde & Brother-in-law \\
Younger brother's wife & Kelyn & Sister-in-law \\
Younger sister's husband & Koueu bala & Brother-in-law \\
Wife's elder sister & Kain bike & Sister-in-law \\
Wife's younger sister/brother & Baldyz & Sister-in-law,brother-in-law \\
Wife's elder brother & Kain aga & Brother-in-law \\
Husband's younger sister & Kain singli & sister-in-law \\
Husband's elder brother & Kain aga & Brother-in-law \\
Husband's younger brother & Kain ini & Brother-in-law \\
Wife's sister's husband & Bazha & Brother-in-law \\
Son's wife's and daughter's husband's father & kuda & \\
Son's wife's and daughter's husband's mother & Kudagai & \\
Male relative on the part of wife's relatives & Kuda bala & \\
Female relative on the part of wife's relatives & Kudasha & \\
\hline
\end{tabular}

From above Tables we see that there are certain similarities and big differences between English and Kazakh kinship terms. According to the Sapir- Whorf Linguistic Relativity Theory every language has its own way of encoding the real world concept which bears a deep relation with national culture (Linguistic Relativity, Wikipedia). Although every language is capable of denoting every kinship relationship conceivable, no language does this. Through liberal use of classificatory terms all societies reduce the number of kinship terms and for this reason it is not always possible to find direct equivalent of kin terms across languages. This is the case when language is selective to the naming of kinship relations. Many Kazakh terms do not have their matching terms in English. Every terminologically identified kinship category is associated with a culturally distinctive pattern of behavior which should be followed in relation to EGO (Murdock, 1949). Terminological identification of a certain relative means that the behavior towards him is different from that of others. For ex.: Sons and daughters of sisters are particularized by a special term $<$ bole $>$. As a rule, sisters maintain affectionate, trustful and supportive relations with each other and they extend these feelings to their children.

Son's wife's and daughter's husband's parents are specified by the terms $<$ kuda $>$ and $<$ kudagai $>$, who are relatives-in-law and the pattern of behavior towards these people should be that of deep respect and good relationship.

There is kinship in theory and kinship in practice. In theory every kinsman is to follow the expected pattern of behavior but in real life things may go on quite differently. Two men who are known as brothers are expected to maintain supportive, friendly relations, but in practice they may be bitter rivals or go their way independently of one another. Even they are "bad" brothers they do not cease to be brothers because as proverb runs "Blood is thicker than water" and this does not invalidate the system of social expectations.

\section{Conclusion}

Kinship for the Kazakhs was the strongest survival strategy. The codes of conduct within a kin group (tribe) strictly observed in the society evolved as a result of the pressures of survival and self-protection of its every member in the conditions of harsh environment. In such conditions people had to concern themselves with the laws of the society and adopt the behaviors that help to survive better and increase reproductive opportunities. Each member of the kin group had a collection of behaviors that ensured better adaptation to the social community and provide self-protection, mate choice, relationship maintenance, parental care and status. An individual's chance of survival increases if he/she belongs to a group that increases its own chance to survival and the survival of a society is ensured by orderly cooperation of different individuals which has a complex relation to the rules of conduct the individuals follow since the eternal truth is that the first law of life is self-preservation and one cannot preserve himself without being concerned about preservation of others.

At present Kazakhstan is an economically fast developing country, transforming into a modern industrialized society, but it does not mean that kinship is insignificant. Kinship bonds are still strong in the contemporary Kazakh community and enjoy importance in people's daily lives. It remains as one of the material and 
psychological protective mechanisms of a person and continues to be important to day. People organize their domestic lives (cooking, eating, speaking, procreation and child care) through the family.

Kinship plays and definitely will play a vital role in constituting and maintaining Kazakh culture throughout its history.

\section{References}

Argynbaev, H. (1975). Semya I brak u kazakhov. Aftoref dis. Doctor, ist.nauk,-Almay.

Argynbaev, H. (1984). The kinship system and customs connected with the ban on pronouncing the personal names of elder relatives among the Kazakhs. Kinship and Marriage in the Soviet Union. Field Studies. London.

Badhesha, R. S. (n. d.). Sapir-Whorf. Retrieved from http://zimmer.csufresno.edu/ johnca/spch100/4-9-sapir.htm Bloom, A. (1981). The Linguistic Shaping of Thought. Hillsdale, NJ: L. Erlbaum.

Hayek, F. A. (1991). The Evolution of Society. In Proceedings of the Scientific-Theoretical Conference "Kazyrgy Kazakh Adebiettanu Gylymy men Adebiet Cynynyng ozekty macelelery” (pp. 244-249). al-Farabi University, Almaty.

Kabakova, M. (n. d.). Family values and traditions of the Kazakhs. Retrieved from http://e-history.kz/ru/ contents/view/440A.L

Kroeber, A. L. (n. d.). Classificatory Systems of Relationship. Journal of the Royal Anthropological Institute, 39, 77-85.

Leach, E. R. (1958). Concerning Trobriand Clans and the Kinship Category "tabu". In J. Goody (Ed.), The developmental cycle in domestic groups (pp. 120-145). Cambridge: Cambridge University Press.

Levy-Strauss. (1969). The Elementary Structure of Kinship (p. 481). Boston.

Linguistic Relativity. (2014, October 12). In Wikipedia, the free encyclopedia. Retrieved October 12, 2014, from http://en.wikipedia.org/wiki/Linguistic_relativity

Lowie R. H. (1928). A note on Relationship Terminologies, 30, 264.

Lowie R. H. (n. d.). Note on Relationship Terminologies (pp. 265-266).

Maurice, B. (2010). Kinship Terms are not Kinship. Behavioral and Brain Sciences, 33(5). Cambridge University Press. Retrieved from http://eprints.lse.ac.uk/35580/

Mckinley, R. (1977). Why do Crow and Omaha Terminologies exist? Man, 6.

Muldagaliyeva, A. A. (2013). Terms of Kinship as the Phenomenon of National Culture.

Murdock, P. M. (1949). Social Structure (p. 224). New York.

Radcliffe-Brown, A. R. (1931). The Social Organization of Australian Tribes. Glencoe, 111. Free press. http://dx. doi.org/10.1002/j.1834-4461.1931.tb00015.x

Radcliffe-Brown, A. R., \& Forde, D. (Eds.). (1950). African Systems of Kinship and Marriage. Oxford University Press. Bloom, A. 1981. The Linguistic Shaping of Thought. Hillsdale, NJ: L. Erlbaum.

Stanford Encyclopedia of Philosophy. The linguistic Relativity Hypothesis. Retrieved from http://plato.stanford.edu/entries/relativism/supplement2.html

\section{Copyrights}

Copyright for this article is retained by the author(s), with first publication rights granted to the journal.

This is an open-access article distributed under the terms and conditions of the Creative Commons Attribution license (http://creativecommons.org/licenses/by/3.0/). 